\title{
La escritura de la lectura. El discurso testimonial de los lectores
}

\author{
Héctor Guillermo Alfaro López *
}

Artículo recibido:

18 de enero de 2005.

Artículo aceptado:

30 de mayo de 2005.

\section{RESUMEN}

A través de los testimonios dejados en registro escrito por los lectores sobre su práctica lectora se formula el esquema de una tipología de los lectores: fácticos y teóricos; así como las categorías de su discurso testimonial: fragmentario y orgánico. La finalidad es que ese esquema sirva a los bibliotecólogos para mejor comprender la práctica de la lectura en su dimensión individual y concreta, lo que a la vez les permitirá tener una visión humanística de los lectores y su actividad lectora.

Palabras clave: Lector; Lectura; Escritura; Tipología; Categorías; Humanismo.

* Centro Universitario de Investigaciones Bibliotecológicas de la UNAM, México. galfaro@cuib.unam.mx INVESTIGACIÓN BIBLIOTECOLÓGICA, Vol. 20, Núm. 40, enero/junio, 2006, México,
ISSN: 0187-358X. pp. 187-202 
The writing of reading.

The testimonial discourse of readers

Héctor Guillermo Alfaro-López

Through testimonies on reading practice left as written record by readers, a scheme is formulated for a reader typology: factual and theoretical, as well as the categories of their testimonial discourse: fragmentary and organic. The purpose is that the scheme gives librarians a better understanding of reading practice and its individual and concrete dimensions, which simultaneously will allow them a humanistic vision of readers and their reading activity.

Keywords: Reader; Reading; Writing; Typology; Categories; Humanism.

\section{I}

unque lectura y escritura no guardan una unidad de continuidad in-
prácticas ha mostrado que se puede saber leer sin necesariamente saber es-
cribir y, al contrario, ejercer la escritura (como, por ejemplo, hacían algunos
copistas de la antigüedad) sin saber leer aquello que se escribía; sin embargo,
establecen entre sí un amplio entramado de relaciones. Al ser estudiada por
separado, cada una de ellas clarifica sus aspectos particulares y diferenciales,
pero al estudiarlas a través de las relaciones que pueden establecer muestran
su extraordinaria complejidad, la cual a su vez deja de manifiesto la sólida rai-
gambre humana que les da forma. Esto puede apreciarse con mayor claridad
cuando ambas establecen una relación en la que una se convierte en reflejo de
la otra; es decir, cuando la escritura describe o explica el proceso y los efectos
de la lectura en los lectores: la escritura de la lectura, en cuanto tal, es el dis-
curso testimonial de los lectores. A través de la escritura varios lectores han
dejado testimonio de lo que para ellos ha significado y representado la lec-
tura. No se trata aquí, pues, de comprender la relación que establecen estas
prácticas a la manera en que la lectura deriva en el ejercicio de cualquier tipo
de escritura, como por ejemplo el investigador que lee gran cantidad de libros
para escribir algún tratado sobre el fenómeno que investiga. Por el contrario, 
el objetivo que aquí se busca dilucidar es una forma de relación menos visible pero sí más profunda: la manera en que la propia escritura explica su relación con la lectura a través de los testimonios de los propios lectores. Objetivo éste del que se deriva otro más: la manera en como esta relación entre escritura y lectura contribuye a que los bibliotecólogos tengan una comprensión concreta y humana de estas prácticas pero más aún de aquellos que la llevan a cabo, los lectores.

Sólo unas palabras sobre dos términos centrales aquí implementados: tipología y categoría. Los términos de carácter técnico que se implementan en una argumentación cognoscitiva tienen la función de contrarrestar la dispersión y ambigüedades que los fenómenos en su movimiento real producen, y ello es condición necesaria para que el pensamiento pueda acceder a su comprensión. Así, los términos técnicos vienen a constituir una especie de perímetro que ubica, delimita y estabiliza (por eso son parte fundamental y estratégica en el proceso de construcción del objeto de conocimiento) el fenómeno, o, más exactamente, la parte o aspecto del fenómeno que se quiere estudiar. Además de que también contribuyen a ponerle límite a las prenociones de las opiniones inmediatas que se producen en la vida cotidiana, y que acaban por ocultar al fenómeno puesto que bloquean o perturban su conocimiento. Los términos de tipología y categoría cumplen aquí la función de suministrar un marco de orden clasificatorio, que a su vez sirve para mostrar la intrínseca relación de conexión lógica entre ambos términos. Tipología significa en este caso una forma de clasificación de los tipos de lectores de acuerdo con la perspectiva del fenómeno aquí estudiado. Y la categoría busca darle orden y jerarquía a las distintas formas de testimonios escritos. Entre la tipología y las categorías hay una correspondencia lógica que permite comprender la articulación entre el individuo (lector-escritor) y sus prácticas (lecturaescritura): tipo de lector y categoría de testimonio. Estos términos funcionan por lo tanto como marco de orden clasificatorio y, en cuanto tal, son una guía que nos conduce a través de nuestro objeto de conocimiento y nos permite alcanzar mejor los objetivos antes indicados en esta investigación.

\section{II}

La lectura es una actividad compleja. Aunque a primera vista se muestre de manera simple: se trata sólo de descodificar un texto. Y esa complejidad no radica unicamente en el largo camino de enseñanza alfabetizadora que desemboca en la descodificación fluida de un texto, ni en los procesos mentales que se suceden durante esa descodificación. Es compleja porque abarca la 
vida interior y exterior del individuo lector; esto es, tanto sus procesos vitales como el mundo que lo rodea. La lectura nos muestra a cada momento aspectos cambiantes, según se la trate de asir o comprender. Se la puede enfocar en perspectiva para comprenderla, como lo hace el estudioso del tema de la lectura; o desde dentro, como lo hace el propio lector cuando deja testimonio de ello; o, en última instancia, aunando ambos enfoques, donde el estudioso del tema utiliza la experiencia y los testimonios de toda índole que dejan de su actividad lectora los lectores. Esto último resulta apropiado para los bibliotecólogos, quienes se interesan o investigan todo lo concerniente al fenómeno de la lectura, puesto que a diferencia de, por ejemplo, los historiadores y los sociólogos, que hacen de la lectura un tema de sus indagaciones, no requieren que los lectores individuales y concretos estén presentes todo el tiempo; es decir, no les es indispensable el testimonio de lectores particulares con nombre propio. Para los historiadores se trata de los lectores, y de las formas de lectura que ya fueron hechas. Mientras que para los sociólogos el lector es la colectividad genérica y la lectura un acto social. Además, tanto para la historia como para la sociología, los lectores no son un objeto de conocimiento central en su visión de la realidad, o, más exactamente, del aspecto de la realidad que es su objetivo.

Por otra parte, para el bibliotecólogo sí es determinante el conocimiento que le pueden aportar los lectores individuales y concretos, porque son ellos los que concurren a las bibliotecas y hacen uso de sus servicios con miras a llevar a cabo su actividad de lectura. De hecho la biblioteca trabaja en función de ellos, de satisfacer sus necesidades de lectura (información). De ahí que para la bibliotecología la lectura sí sea un objeto de conocimiento central. Así pues, el conocimiento directo del lector y la lectura está en consonancia con los supuestos cognoscitivos de su disciplina. Lo que no significa que sea éste el único enfoque que ha de seguir el bibliotecólogo, pues de hecho puede y debe hacer uso de enfoques más complejos y abstractos desde supuestos, incluso, elaboradamente teóricos, como se explicará más adelante. Pero aquí se trata de expresar la pertinencia fundamental del enfoque inmediato y directo que le procuran los lectores individuales, aquellos que son de "carne y hueso" (como diría Unamuno).

Los testimonios que han dejado y dejan los lectores son de diversos tipos. Aunque cabe subrayarse que aquí nos referimos, obviamente, al testimonio que ha quedado como información registrada, acorde con los mismos supuestos de la bibliotecología, y no a aquellos testimonios volátiles que se hacen al calor de la conversación. Se trata, pues, del testimonio que han dejado por escrito los lectores, el cual no es homogéneo, por lo que para su mejor inteligibilidad adelantaré un esbozo provisorio de esquema clasificatorio dividido en una tipología de los lectores que han dejado testimonio escrito sobre 
su actividad lectora, así como una categorización de los testimonios escritos dejados por ellos, tal esquema puede ilustrarse de la siguiente manera:

Tipología de lectores

I. Fáctico

\section{Categoría de Testimonios}

$\left\{\begin{array}{l}\text { 1. Fragmentario } \\ \text { 2. Orgánico }\end{array}\right.$

$\left\{\begin{array}{l}\text { 3. Fragmentario } \\ \text { 4. Orgánico }\end{array}\right.$

Nuevamente cabe señalar que tal esquema es sólo un esbozo cuya función es darnos un orden y servirnos de guía en el seguimiento del tema aquí tratado. Asimismo, por su propio carácter temático esta indagación se encuentra inscrita dentro de ese universo que Michel Foucault definió como el orden del discurso, ${ }^{1}$ donde el lector se convierte en palabra escrita (discurso escrito) que testimonia su ser lector y su hacer lector, para ser leído por otro lector: espejo de lectores. Palabra leída que se transfigura en palabra escrita.

No todo lector ha dejado testimonio sobre el ejercicio de su actividad lectora; de hecho, a la inmensa mayoría de lectores que han existido jamás se les ha ocurrido dejar testimonio escrito de ello. Lo cual se entiende porque en primera e incluso última instancia lo que le interesa al lector es leer; la lectura es la que hace de él un lector. Y mientras la lectura llene las necesidades por las que el lector acudió a ella, éste no irá más allá. Además la lectura como actividad que proyecta al lector hacia el interior de un texto en el que encuentra satisfacción, y que por lo tanto lo mantiene cautivo, no lo impulsa a salir de ese largo horizonte de textualidad leída para dejar testimonio de esa inmersión. Del mismo modo muchos lectores no sienten el mismo agrado hacia la lectura que hacia la escritura, para la cual incluso se consideran incapacitados. Y finalmente, porque muy coherentemente se dirán “¿Qué sentido tiene escribir sobre mi lectura y mi yo-lector si lo importante y lo que me interesa, es leer? por eso soy lector y no escritor." Desde la contundencia de este argumento, no es poca la razón que estos lectores esgrimen para no dejar testimonio escrito de su actividad lectora. Pero con ello nos cierran las posibilidades de ver cómo desde la especificidad y diferencia de un individuo que no es igual a otro, toma el primero conciencia de sí mismo a través de la lectura, lo cual podría ser un estímulo y guía para que otros comenzaran a leer 
o perseveraran en la lectura. Esto sin considerar que, como en el caso de los bibliotecólogos que estudian esos testimonios, tal hecho los limita para comprender las particularidades y cualidades de la lectura que se corresponde, de múltiples maneras, con la lectura que llevan a cabo aquellos que concurren a una biblioteca. Además para un bibliotecólogo conocer testimonios de lectores también le permite captar en sí mismo los procesos transformadores de la lectura y, a partir de ello, actuar en consonancia respecto a su temática de indagación y a su campo de conocimiento: lo que puede repercutir en la reconstitución de los servicios de la biblioteca para satisfacer necesidades concretas y específicas de lectores, quienes, además, no son una entidad homogénea y neutra, sino individuos particulares y diferenciados.

\section{III}

Los dos tipos de lectores señalados han sido considerados así desde una perspectiva analítica para su mejor comprensión, pero no se trata de entidades fijas, inmutables o aisladas; de hecho en términos reales se dan combinaciones o amplias gradaciones entre ambos. Así, puede haber lectores testimoniales en los que se combinen ambos tipos, o que oscilen en su testimonio de uno a otro de esos tipos de lector, por lo que el tipo de lector se constituiría en función de la categoría de los testimonios indicados en la gráfica. Así pues, el tipo de lector se constituye en función de la categoría de testimonio que deja registrado por escrito. La lectura es un fenómeno en movimiento, tiene su propio élan vital, pero al pasar al registro escrito como testimonio entra en el orden del discurso y, en cuanto tal, puede ser comprendido cognoscitivamente. Las categorías de los testimonios pueden considerarse como variaciones de la orientación con que el lector asume y lleva a cabo su lectura, la que al plasmarse en su testimonio muestra una diferencia organizativa del discurso. Pero también ello revela las diversas formas en que es vivida transformadoramente la acción de la lectura sobre el lector. Comencemos por la comprensión del lector que aquí defino como fáctico; esto es, el lector que lleva a cabo su lectura sin mayores preocupaciones reflexivas sobre el sentido o esencia de la misma; es la lectura de la inmediatez. El testimonio que deja sobre ella puede ser de dos clases, que vienen a ser las dos categorías anunciadas: fragmentario y orgánico. Tenemos asi un tipo de lector fáctico cuyo testimonio puede dividirse en las categorías de fragmentario u orgánico; esto es, según la diferencia organizativa del discurso.

El lector fáctico sólo se dedica a leer libro tras libro buscando absorber, vivir, conocer la información que se le ofrece en el texto leído, sin hacerse 
mayores cuestionamientos y reflexiones al respecto. La lectura por eso le es, en cuanto tal, un objeto fáctico, cotidiano, y cuando deja testimonio de esto, como por ejemplo en la categoría de fragmentario, nos ofrece esquirlas, atisbos, impresiones instantáneas de lo que la lectura en conjunto o alguna o algunas lecturas en particular le significaron para su vida o su pensamiento, pero que en cuanto tal no conforman una visión unitaria, concatenada y argumentada de lo que en términos amplios representó para su vida o la impactó. La literatura está saturada de tales testimonios fragmentarios. Por mediación de personajes literarios, que son un alter ego del escritor, se dan opiniones, o se hacen observaciones o remembranzas sobre la significatividad de la lectura de una o varias obras y de lo que representó en la vida de esos personajes (escritores). Incluso en otros géneros no son tan inusuales tales testimonios, así por ejemplo en filosofía es famosa esa esquirla testimonial de Kant que decía que la lectura de las obras del filósofo inglés David Hume lo "habían despertado de su sueño dogmático", lo cual ha de entenderse como que esa lectura transformó su vida, mas al ser Kant un filósofo esto significaba también que había cambiado su manera de pensar y practicar la filosofía, lo que redundó en la elaboración de su filosofía crítica, por la que es justamente conocido. No es inusual que lectores que no fueron escritores en el sentido profesional del término dejaran en diarios, memorias o cartas fragmentarias testimonios de la acción transfiguradora de la lectura en sus vidas. Pero esos testimonios sólo nos muestran aspectos fraccionales, muy parciales de la influencia de la lectura en la vida de todos aquellos que dejaron esta clase de testimonio, como si más bien la lectura sólo hubiera pasado aleteando sobre ellos, y tocado partes muy localizadas de sus vidas, pero esta impresión en buena medida es producto de lo fragmentario del discurso testimonial, que por lo mismo no nos permite apreciar con una exposición amplia y concatenada la acción profunda y continua de la lectura y de cómo los transformó de manera radical. Durante largo tiempo y hasta la fecha, esta categoría de testimonio parcial es la que ha predominado y proliferado; lo cual se entiende porque no exige una autoindagación intensa y extensa respecto al proceso removente de la lectura en la vida personal, íntima, del lector para luego ser expuesta discursivamente. Basta con mostrar algunos atisbos y dejar flotando los supuestos para considerar que eso es suficiente. Pero la otra categoría de testimonio nos muestra que no basta con ello.

El testimonio orgánico representa en el orden del discurso un paso de mayor elaboración y complejidad respecto a la categoría precedente. Es ésta una categoría donde queda patente y argumentado el largo recorrido transformador que la lectura lleva a cabo en la vida de aquél que ha elegido el destino de ser un lector. También la literatura nos ofrece excelsos ejemplos de tal 
categoría testimonial, por ejemplo aquellas novelas o relatos donde la lectura es precisamente el tema, y donde hasta el personaje principal nos muestra con lujo de detalles la acción que ha desempeñado la lectura en su vida, que asimismo es un alter ego del escritor; como lo reflexiona Ricardo Piglia en su fascinante ensayo El último lector, donde muestra las múltiples y complejas relaciones que se dan entre literatura, lectura y realidad o, en otras palabras, la lectura y su acción transformadora de la vida del lector; un bello ejemplo de esto lo tenemos con la novela Balzac et la petite tailleuse chinoise donde el narrador, que es la voz del propio escritor Dai Sijie, nos explica cómo la lectura le ayudó a sobrevivir y construir su vida futura aún por encima de las más terribles condiciones de represión política en China. Pero una forma muy depurada de esta categoría es la que nos ofrece la investigadora Michéle Petit, tanto respecto a sí misma como sobre aquellos lectores en quienes ella centra su atención. M. Petit pide y promueve, porque ella lo ha llevado a cabo respecto a sí misma, la escritura de la autobiografía de los lectores, precisamente en cuanto lectores. En el capítulo final de su libro Lecturas del espacio intimo al espacio público ${ }^{2}$ escribe su autobiografía "Del Pato Donald a Thomas Bernhard. Autobiografía de una lectora nacida en París en los años de posguerra" donde con precisión no exenta de un exquisito sentido, lírico muestra paso a paso su formación como lectora, y nos cuenta cómo la lectura transformó radicalmente su vida e incluso la orientó hacia la indagación sobre los efectos que produce la lectura, principalmente en los jóvenes; a quienes escucha narrar su autobiografía lectora para ella a su vez plasmarla testimonialmente. Es decir, comprendiendo a fondo las implicaciones cognoscitivas y prácticas que conlleva la escritura de semejante autobiografía, pide a los lectores de cualquier latitud y de cualquier edad que emprendan esa autobiografía lectora. Empresa que clarifica los aspectos y los alcances de la lectura en la vida de cada individuo, lo que en términos prácticos le permite a ella conocer los problemas, carencias y necesidades de los lectores, y así poder actuar en consonancia para encontrar soluciones a lo planteado. Mas para lo que aquí se argumenta, esta clase de testimonios orgánicos le permiten al bibliotecólogo una visión más clara y precisa del contínuum transformador de la lectura en la vida de los lectores individuales. Si, como solicita M. Petit, cada vez mayor número de lectores escribiera su autobiografía se tendría una cartografía intelectual y espiritual más completa de los efectos de la lectura a lo largo de la vida de los lectores, lo que ayudaría a los bibliotecólogos a tener una visión más humana y humanística, de los lectores, quienes por lo

2 (Col. Espacios para la lectura) México, FCE, 2002. Véase la reseña que sobre este libro hago en Revista de Investigación Bibliotecológica: Archivonomía, bibliotecología e información, vol. 18 , no. 36, enero-junio, 2004, CUIB-UNAM. 
mismo, serían algo más que meros usuarios de la información en medio de una biblioteca.

\section{IV}

El segundo tipo de lector es aquél que denomino teórico y cuyo testimonio se divide de manera análoga a las categorías precedentes en fragmentaria y orgánica. El lector teórico, entendiendo teórico como estructura concatenada y sistemática de reflexión, es aquél que no se conforma con la mera lectura fáctica, inmediata y vivencial del texto, sino que toma distancia de ella para comprenderla en perspectiva. Y desde esa perspectiva lleva a cabo una reflexión sobre el sentido o el ser de lo que para él representa la lectura, pero también lo que ésta le significa per se, con lo que su testimonio adquiere la tonalidad teórica; visión concatenada y sistemática (aun sobre lo fragmentario del testimonio) de conceptos sobre la lectura. Así pues, este segundo tipo es el lector teórico cuyo testimonio se divide en las categorías de fragmentario y orgánico.

Este tipo de lectores representa un segmento muy breve de la totalidad de los lectores, de hecho, son rara avis. En ellos se da la trasmutación de la lectura de objeto fáctico a objeto de conocimiento, lo que por otra parte entraña una mayor elaboración cognoscitiva del discurso. Estos lectores suelen tener una natural inclinación hacia la esfera abstracta que proyectan sobre aquello que leen, por lo que la o las lecturas hechas a lo largo de su vida sufren una transfiguración abstracta que se revierte sobre la propia lectura para tratar de contestar a la pregunta básica a todo tipo de discurso testimonial teórico: ¿qué es la lectura? o en su variante ¿cuál es el sentido de la lectura? A diferencia de la pregunta implícita que se plantea el lector fáctico ¿cómo me ha trasformado, construido vivencial y humanamente la lectura? La respuesta a la primera pregunta es múltiple y depende de la manera en que previamente han asumido y llevado a cabo su vida lectora los lectores teóricos. Lo que a su vez puede derivar en una concepción práctica de la escritura. No pocos de los lectores teóricos son también escritores y sus visiones teóricas de la lectura entroncan directamente con su concepción de la escritura: círculo de símbolos donde se construye la vida, el pensamiento y la obra de tales lectores-escritores. Como nos extenderemos explicativamente con un ejemplo de testimonio fragmentario teórico, su explicitación la llevaremos a cabo después del testimonio orgánico.

Tal testimonio consiste en un discurso que, breve o extenso, expresa una concepción unitaria y completa de una teoría de la lectura; por supuesto dentro 
del pequeño sector de lectores teóricos, el número de aquellos que llegan a escribir o argumentar una teoría orgánica de la lectura es aún más reducido. La exposición y explicación que logran hacer de una teoría de la lectura es entonces todo un acontecimiento, es la cúspide de los testimonios sobre la lectura. En la elaboración de tales testimonios es común la aportación de intelectuales de distintas disciplinas, aunque algunos escritores particulares, como se dijo, han forjado importantes e interesantes teorías de amplio aliento y el pensamiento aéreo de la palabra escrita, para forjar una teoría explicativa que busca dar razón del sentido de la lectura. Ese afán reflexivo es muestra de la necesidad de clarificarse esa actividad en apariencia circunstancial, para darle un fundamento completo, orgánico, el cual viene a ser una especie de ventana a través de la cual se comunican explicativamente el mundo del texto y el mundo del lector, tal como los define Paul Ricoeur. ${ }^{3}$ Un ejemplo de esta categoría de testimonios es también el que elaboró Freud, en su libro Psicopatología de la vida cotidiana que incluye un capítulo intitulado "Equivocaciones en la lectura y la escritura", donde, a pesar de la brevedad expositiva y explicativa, desarrolla Freud una compleja teoría de la lectura que se articula con su teoría psicoanalítica, o, más exactamente, extiende hacia ella, pero que tomada en sí misma es una teoría completa ${ }^{4}$ que da explicación de los efectos de la lectura en el inconsciente del lector. Por su alto nivel de elaboración y complejidad, que de una u otra forma subsume a las demás categorías testimoniales, el testimonio teórico orgánico es aquél que brinda una visión más completa y depurada para el conocimiento de la dimensión testimonial de la lectura.

La otra categoría: un testimonio teórico fragmentario es aquél discurso elaborado con esquirlas o fulgurantes atisbos conceptuales que no alcanzan a constituirse por sí mismos en una visión teórica concatenada de la lectura. Sin embargo puede darse el caso de que esos diversos fragmentos que deja uno de estos lectores esparcidos a lo largo de sus textos, al conjuntarse pueden mostrar su unidad y sistematicidad, y constituyan un testimonio teórico concatenado. Esas esquirlas teóricas pueden por sí mismas también ser ya el germen de una concepción teórica de largo alcance; pueden aparecer en el centro de la argumentación de un texto cuyo tema principal versa sobre otras cuestiones; o pueden estar ubicadas en la periferia como una piedra preciosa que adorna algún rincón del texto. Esos fragmentos son básicamente un conato de teoría. En no pocos casos son un producto que emerge en medio del decurso de la lectura; esto es, que no han sido objeto de una continua y exclusiva elaboración

3 P. Ricoeur, Temps et récit, Paris, Seuil, 1985.

4 Sobre esa teoría freudiana de la lectura hago un detallado análisis y una explicación, mostrando su pertinencia para la Bibliotecología, en mi estudio: "La otra lectura. Una contribución al problema de la lectura en Bibliotecología”, en Revista Investigación Bibliotecológica. 
reflexiva, y que, a diferencia del testimonio orgánico, son una destellante iluminación que surge en la conciencia del lector y le permite comprender en perspectiva el sentido de la lectura, para después extinguirse ese fulgor entre el fluir del texto. Tal lector no necesariamente tiene el objetivo de formar una teoría sino quizá de formarse referentes teóricos, atalayas desde donde contempla (contemplación, es el sentido original y primario de teoría, cuyo origen etimológico recordémoslo es el verbo griego theorein, contemplar) el discurrir de su lectura, pero que pueden tener alcance universal. Veamos todo esto con un ejemplo que nos proporciona el gran escritor Jorge Luis Borges.

Borges fue uno de los grandes lectores de la historia, y no por la cantidad de libros que leyó sino por la forma en que los leyó, lo cual le dio una lúcida conciencia lectora sobre todas las implicaciones y complicaciones que conlleva la lectura. Su obra en conjunto bien podría definirse como la conciencia de la lectura. Conciencia que por momentos se alzó incluso por encima de ella misma para formular una consistente teoría de la lectura. Su obra en conjunto, bien podría definirse como la conciencia de la lectura. Conciencia que por momentos se alzó incluso por encima de ella misma para formular una consistente teoría de la lectura -que bien podría ubicarse dentro de los testimonios orgánicos-, pero más allá de esa organicidad pobló sus textos de innumerables esquirlas que por sí mismas son gérmenes de teorías, y que en algunos casos sólo son un fugaz atisbo de gran riqueza por su universalidad, que nos invita a ahondar en ellos para comprender toda la magnitud de lo que ese minúsculo fragmento encierra. Una de esas esquirlas aparece de una manera tramposamente incidental en un breve texto que es el resumen de una conferencia titulada Mi primer encuentro con Dante. Y digo tramposamente incidental porque aunque más parecen frases brillantes de circunstancia para justificar su dilación al leer la Divina Comedia, de hecho son el eje que sostiene y sobre el que gira su texto. Esas frases, que son explicitación a su vez de una frase, dicen:

Una frase corriente habla de releer a los clásicos. Esto, que suele ser una hipocresía, puede asimismo significar que todos los hemos leído, sin el ocioso tramite preliminar de abrir el volumen y pasar de una página a otra. Significa que hay obras que han entrado en la memoria general de los hombres y cuya lectura es siempre una relectura. ${ }^{5}$ 
Veamos la idea que subyace en esta aparentemente observación pasajera de Borges, ${ }^{6}$ que nos conducirá a su visión teórica de la lectura, sobre la cual además se sustenta su propia obra escrita. En las palabras iniciales: "Una frase corriente habla de releer a los clásicos" nos refiere a un lugar común en el universo de la lectura que hace una división entre las obras y la forma en cómo han de ser éstas leídas: los clásicos y los demás libros. Los primeros son la élite que ha resistido la erosión del tiempo y los cambios históricos que a la mayoría de tantas obras ha hecho sucumbir; así, lo clásico viene a ser sinónimo de perennidad. Los clásicos tienen valores propios que los distinguen y elevan por encima de las demás obras; tales valores son la unidad que conjuga diversos elementos: estilo, enfoque, tema, etcétera, que terminan por dar como resultado una obra que contiene lo universal y que le dice algo profundo a cada individuo (lo cual puede cambiarle su visión del mundo e incluso la vida), en cualquier época histórica. ${ }^{7}$ Así por ejemplo la Divina Comedia, que es lo que motiva el texto de Borges, sigue y seguirá siendo leída por innúmerables generaciones futuras de lectores. Pero esta élite de obras universales se lee no una sino varias veces, a diferencia de las otras para las que basta con hacer una sola lectura y que a veces incluso esto sería recomendable soslayar.

Borges continúa el párrafo con una réplica:

Esto, que suele ser una hipocresía, puede asimismo significar que todos hemos leído, sin el ocioso trámite preliminar de abrir el volumen y de pasar de una página a otra.

El argumento de la relectura de los clásicos puede obrar de dos formas: primero como una hipocresía que exonera al individuo de leerlos o, en su refinada variante, como un hacer creer que, después de no haberlos leído, emprenderá una vez más su necesaria relectura. A la clásica pregunta: ¿Ya leíste este libro clásico? Las respuestas no menos clásicas son: "Sí como no, todo hombre culto debe leerlo", o, "lo releo periódicamente" o, "ya lo leí pero tengo proyectado volverlo a leer" La segunda forma es que sin haberlos leído, de una enigmática manera ya han sido leídos sin siquiera haber posado los ojos en el texto. Porque su misma calidad de clásico y su prolongada presencia a través de las épocas históricas han logrado que aspectos particulares

6 Sobre esa clase de tramposas observaciones pasajeras Freud expreso sabias palabras, que señalan todas las implicaciones que se les pueden extraer: "Sé muy bien que una cosa es expresar una idea bajo la forma de una pasajera observación, y otra tomarla en serio, conducirla a través de todos los obstáculos y conquistarle un puesto entre las verdades reconocidas". Freud, S., Historia del movimiento psicoanalítico, O. C. T. 2, Madrid, Biblioteca Nueva, 1948, p. 893.

7 Italo Calvino. Por quéleer a los clásicos, Barcelona, Tusquets, 1992. 
o multiformes síntesis o reproducciones de ellas, se desgranen de la obra y circulen por doquier para conocimiento de sus imposibles lectores. Así refiriéndose al Dante, Borges nos habla de esa proliferación de esquirlas de la obra:

En el caso de la Divina Comedia ocurre también que todos han leído o escuchado, los primeros tercetos del infierno o el fin del canto quinto, que algo se les alcanza de Ugolino y que es difícil, o imposible, no haber visto las ilustraciones románticas de Doré. Existe el peligro de suponer que esas posesiones casuales equivalen al estudio de la Comedia. ${ }^{8}$

Esto que podemos llamar lectura sustituta de un clásico, que se ha dado en todos los tiempos, en la época presente alcanza un grado inflacionario extremo debido a los medios masivos de comunicación que retoman esas esquirlas de las obras clásicas para reproducirlas ad infinitum, lo cual entra dentro de aquello que Walter Benjamín llamaba la obra de arte en la época de su reproducción mecánica. ${ }^{9}$ Según esta teoría la obra de arte original ha sido desplazada u ocultada por su reproducción mecánica, lo que causa que se pierda el aura de la obra original sobre la cual sólo se tiene la percepción de algunos aspectos o una visión deformada. Y lo mismo sucede con los libros clásicos, que ante tantas reproducciones: imágenes, frases, segmentos, resúmenes de la obra clásica "ya se han leído" sin acometer el ocioso trámite de pasar de una a otra página. ${ }^{10}$

Esa lectura sustituta adquiere para Borges un carácter positivo y justificado puesto que "significa que hay obras que ya han entrado en la memoria general de los hombres y cuya lectura es siempre una relectura”. Lo que puede interpretarse como que esas obras clásicas al desbordar su contenido el breve perímetro de sus páginas para circular, a través de múltiples canales, en la vida cotidiana de los hombres, incluso transformando esa vida con la hondura de su mensaje universal, han pasado a formar parte de la memoria humana

8 J. L. Borges. op. cit., p. 72.

9 “On pourrait réunir tous ces indices dans la notion d' aura et diré: ce qui, dans l'oeuvre d'art, à l'époque de la reproduction mécanisée, dépérit, c'est son aura. Processus symptomatique dont la signification dépasse de beaucoup le domaine de l'art. La technique de reproduction -telle pourrait être la formule générale-detache la chose reproduit du domaine de la tradition. En multipliant sa reprodution, elle met à la place de son unique existence son existence en série et, en permettant à la reprodution de s'offrir en n' importe quelle situation au spectateur ou à l'auditeur, elle actualise la chose reproduite". Benjamín, Walter, "La oeuvre d'art à l' époque de sa reproduction mecanisée”, en Écrits français, (Bibliothéque des idées) Paris, Gallimard, 1997, pp. 142-143.

10 Es más, la posesión vicaria de esos fragmentos ya legitima la no lectura del clásico. ¿Para qué leerlo? es un decir común, si se cuenta con tan gratificante acervo de esquirlas que ahorra la pesadez de una larga lectura. 
sin necesidad de haber sido leídos. Por eso de forma inmediata se sabe de qué tratan antes de abrir sus páginas por primera vez, y conforme se van leyendo nuestra memoria proyecta esa previa lectura, no hecha, sobre ésa que viene a ser, así, una relectura. Esa obra que se lleva en la memoria general pasa a ser de esa manera como una entelequia que desde un inmarcesible topos uranos se proyecta sobre el texto concreto, particular "releído", y transforma nuestra vida. Por eso todo incipiente lector inicia su camino en los libros con un amplio acervo en la memoria, el cual actualiza, transforma, incrementa y reinventa con la lectura de los textos concretos. De este modo toda lectura es una relectura, la escritura es una reescritura. Este último giro de la tuerca es el que nos puede ayudar a comprender la doble dimensión en que se agitan las citadas palabras de Borges, que nos llevó de una concepción universal de la lectura a una lectura particular y de allí a la escritura, que es finalmente su propia escritura, es decir, su concepción de la escritura.

Pocos escritores han tenido como Borges la lucidez para comprender la profundidad de los canales que establece la circulación entre lectura y escritura. Para él, escritor que se sintió detentador de la cultura universal y que además vivió en una era de sobreabundancia informativa, la escritura es resultado de la absorción, la asimilación completa del universo de la lectura. No se inventa nada nuevo, sólo se recrea imaginativamente lo ya existente. Se escribe con base en lo que se lee. El escritor se construye en cuanto tal a partir de lo que ha leído. Y lo que ha leído en su dimensión esencial y que es más determinante para su escritura son aquellas obras clásicas que han ingresado a la memoria general, como la Divina Comedia, que nutrió la escritura de Borges. En este hermoso texto Mi primer encuentro con Dante, Borges o, más exactamente en sus términos, la relectura del gran poema, lo ha transformado, así nos lo dice en esas inolvidables y profundas palabras con que cierra la escritura de su texto:

Hay una primera lectura de la Comedia; no hay una última, ya que el poema, una vez descubierto, sigue acompañándonos hasta el fin. Como el lenguaje de Shakespeare, como el álgebra o como nuestro propio pasado, la Divina Comedia es una ciudad que nunca habremos explorado del todo; el más gastado y repetido de los tercetos puede, una tarde, revelarme quién soy o qué cosa es el universo. ${ }^{11}$

Ese es el poder de la perseverancia y presencia de los clásicos dentro de sus lectores: revelarnos quiénes somos o qué cosa es el universo una tarde cualquiera. Palabras que bien podría haberlas dicho cualquier lector fáctico, 
pero que en este caso son el colofón de lo que un lector teórico ha dicho sobre su concepción de la lectura. Para Borges la lectura de los clásicos le reveló quién era él: un escritor, y le reveló que el universo es un tejido de símbolos escritos que pueblan la memoria general de los hombres; escritor al que si los dioses le son propicios, como en el caso de Borges, harán que sus obras se conviertan en clásicos.

En síntesis, el testimonio que Borges nos deja como lector teórico en su breve y leve observación es que la lectura, aunque no se lleve a cabo en un texto concreto, forma parte de la memoria de la humanidad, donde están contenidas las grandes obras y desde ahí impregnan y determinan la vida de los individuos. Si uno de esos individuos actualiza esa memoria con la "relectura" de uno de esos clásicos que la alimentan puede transformar su vida, al grado de que incluso puede determinar su vocación para escribir libros, los que a su vez podrán enriquecer esa memoria de la humanidad, con lo que el círculo de fuego de la lectura y la escritura se cierra.

\section{Conclusión}

Después de este recorrido a través del esbozo aquí desarrollado de una tipología de lectores testimoniales y de la categorización de esos testimonios de la lectura podemos, como en una visión panorámica, comprender las diversas posibilidades de cómo los lectores llevan a cabo la lectura y de cómo se ven a sí mismos en relación y en función de tal actividad. Esto de manera particular para el bibliotecólogo, a quien le está dedicada esta investigación, puede ser un instrumento de gran utilidad que le permita comprender, a través de los mismos testimonios de los lectores de "carne y hueso", cómo viven y piensan la lectura. Lo que asimismo le podría ayudar a recuperar y redimensionar el fondo humanístico que entraña el acto de la lectura: humanismo lector que queda palpablemente de manifiesto con los testimonios de los lectores fácticos. Pero también le muestra que ese acto humano, precisamente por serlo, conduce a una comprensión teórica de la lectura. Lectores humanos ejerciendo su humanidad en su más alta expresión cognoscitiva, al formular, ya sea fragmentaria u orgánicamente, una explicación que les permita comprender el sentido de ese complejo y misterioso acto de leer. Tal vez porque intuyan que con esa comprensión teórica se explican a sí mismos en su humanidad.

En tales testimonios teóricos puede el bibliotecólogo encontrar los elementos para con ellos elaborar sus propias explicaciones conceptuales, teóricas de la lectura desde los parámetros de su disciplina, con lo que también él vería en sí mismo esa trayectoria que la lectura conlleva desde su dimensión 
fáctica y teórica para desembocar en el humanismo que se reconoce cognoscitivamente a sí mismo a través de la lectura.

París, Maison du Mexique, otoño 2004.

\section{BibLIOGRAFÍA}

Benjamín, Walter, Écrits français, (Bibliothéque des idées), Paris, Gallimard, 1997.

Borges, J. L., Textos recobrados 1956-1986, Buenos Aires, EMECE, 2003.

Bourdieu, Pierre, Choses dites, Paris, Minuit, 1987.

Calvino, Italo, Por qué leer a los clásicos, Barcelona, Tusquets, 1992.

Chartier Anne-Marie, Enseñar a leer y escribir. Una aproximación bistórica, México, FCE, 2004.

Derrida, Jacques, De la grammatologie, Paris, Minuit, 1967.

Foucault, M., L'ordre du discours, París, Gallimard, 2003.

Freud, S., Historia del movimiento psicoanalítico, O. C. T. 2, Madrid, Biblioteca Nueva, 1948.

Petit, Michéle, Lecturas del espacio íntimo al espacio público (Col. Espacios para la lectura), México, FCE, 2001.

Piglia, Ricardo, El último lector, Barcelona, Anagrama, 2005.

Ricoeur, P., Temps et récit, Paris, Seuil, 1985.

Sijie, Dai, Balzac et la petite tailleuse chinoise, Paris, Gallimard, 2002. 